\title{
«EI hambre le impulsara»: La crisis de subsistencias y el auge de delitos contra la propiedad en Galicia durante la década de 1850*
}

\author{
Enrique Carballo Gende ${ }^{1}$ \\ Universidade de Santiago de Compostela \\ enrique.carballo.gende@gmail.com
}

RESUMEN: En la década de 1850 los tribunales gallegos se encontraron con un importante incremento de los delitos contra la propiedad, tanto en términos absolutos como relativos, que coincide con la crisis de subsistencias y el aumento del precio de los alimentos. Aumentaron los robos y hurtos cometidos por individuos asentados dentro de su comunidad y sin antecedentes, en especial provenientes del proletariado rural. Delinquieron para subsistir en un contexto en el que los riesgos asociados a este tipo de crimen eran altos y el sistema judicial no se mostraba tolerante con el delito de supervivencia. La persecución no partió mayoritariamente de los cuerpos policiales. Los primeros pasos para llevarlos a los tribunales los dieron los ciudadanos: las víctimas, vecinos, y, en alguna ocasión, familiares de los delincuentes. Sobre todo en el campo, recurrieron principalmente a las élites locales ligadas a la administración municipal para la denuncia. El castigo hacia los delincuentes pasó, tanto o más que por las condenas de cárcel, por los gastos asociados al juicio, tan onerosos que arruinaban a los acusados totalmente aunque no fuesen condenados.

PAlabras ClaVE: crimen; delincuencia; historia social; delito contra la propiedad; crisis de subsistencias; Galicia.

\footnotetext{
* Miembro del Grupo de Investigación HISTAGRA-USC (GI-1657) del Sistema Universitario Galego, SUG. Referencia Proxectos Plan Galego de I+D (ED431C 2017111).

Para el marco de este trabajo, agradezco sus comentarios al profesor Miguel Cabo Villaverde, mi director de tesis, que realizó una primera revisión del original y me ayudó a orientar la investigación.

Siglas utilizadas: Archivo del Reino de Galicia, A Coruña (ARG); Archivo Municipal de A Coruña (AMC).

${ }^{1}$ ORCID iD: https://orcid.org/0000-0001-6172-0712.
}

Copyright: (C) 2020 CSIC. Este es un artículo de acceso abierto distribuido bajo los términos de una licencia de uso y distribución Creative Commons Reconocimiento 4.0 Internacional (CC-BY 4.0) 
"El hambre le inpulsara": The subsistence crisis and the boom in crimes against property in Galicia during the $1850 \mathrm{~s}$

ABSTRACT: In the decade of the 1850s, Galician courts witnessed a significant increase in crimes against property, both in absolute and relative terms, which coincided with a subsistence crisis and increase in food prices. There was a rise in thefts and pilferage committed by ordinary people, integrated in their communities and without criminal records, especially among the rural proletariat. They stole to subsist, despite the high risks that this kind of crime involved, and the intolerance shown by the judicial system towards this kind of survival crime. Most prosecutions were not initiated by police forces, but by ordinary people: theft victims, neighbours and, sometimes, perpetrators' relatives. In the countryside, particularly, the complainants informed local elites connected to local government. Rather than jail sentences, the crimes were punished by the imposition of the costs of the trial, which were so expensive that even defendants who were not condemned became utterly ruined.

KEY WORDS: crime; delinquency; social history; crime against property; subsistence crisis; Galicia.

CÓMO CITAR ESTE ARTÍCULO/CITATION: Carballo Gende, Enrique, «El hambre le impulsara»: La crisis de subsistencias y el auge de delitos contra la propiedad en Galicia durante la década de 1850», Hispania, 80/264 (Madrid, 2020): 169-199. https://doi. org/10.3989/hispania.2020.006.

Este artículo surge de la identificación de una tendencia presente en las estadísticas judiciales españolas de mediados del siglo XIX: el recrudecimiento del delito contra la propiedad a mediados del periodo isabelino. En 1843, se juzgó a 10.425 personas por delitos contra la propiedad ${ }^{2}$, incluyendo entre ellos algunos tipos como las talas y daños en montes y paseos y los incendios casuales, de entre los 38.620 acusados cuyas causas se fallaron. No sabemos a cuántos delitos corresponde esta cifra, pero, si sigue la misma proporción que el conjunto, serían unos 3.780 delitos $^{3}$. En el periodo 1859-1862 tenemos una media anual de 20.741. Probablemente la desproporción sea menor de lo que parece, $y$ la segunda estadística parece más exacta. Pero en 1883, con una población significativamente mayor, la cifra disminuye hasta los 11.962 casos $^{4}$.

Entre la primera y la segunda medición se implanta el Código Penal de 1848-1850, y entre la segunda y la tercera, el de 1870. Pero la legislación acerca de robos y hurtos, que constituyen la inmensa mayoría de los crímenes contra

\footnotetext{
2 Gaceta de Madrid, 14-02-1845: 1-2.

3 El número de delitos ese año es de 14.005.

${ }^{4}$ Los datos pertenecen a las estadísticas gubernamentales elaboradas para esos años y se han recuperado de GIMENO AGIUS, 151 (Madrid, 1885): 498-501.
} 
la propiedad en 1859-1861 y en 1883, es muy parecida en ambos códigos. En 1859-1862 se registraron 14.445 hurtos anuales; en 1883 eran 8.861, pese a la mayor población. Hubo 3.919 robos anuales contra 1.809 en 1883, y también más daños contra la propiedad, falsificaciones y fraudes.

El comportamiento de los delitos contra la propiedad es lo suficientemente diferente del conjunto de crímenes y del otro apartado principal, el de delitos que se cometen contra las personas, como para hacernos descartar una mejor medición del crimen en 1859-1862.

GRÁFICo 1. Estadística criminal de España para 1843, 1859-1862 y 1883

\begin{tabular}{|l|c|c|c|c|c|c|}
\hline $\begin{array}{c}\text { Categoría } \\
\text { criminal }\end{array}$ & $\begin{array}{c}\mathbf{1 8 4 3} \\
\text { (acusados) }\end{array}$ & Porcentaje & $\begin{array}{c}\text { Media de } \\
\mathbf{1 8 5 9 - 1 8 6 2} \\
\text { (delitos) }\end{array}$ & Porcentaje & $\begin{array}{c}\mathbf{1 8 8 3} \\
\text { (delitos) }\end{array}$ & Porcentaje \\
\hline $\begin{array}{l}\text { Contra las } \\
\text { personas }\end{array}$ & 17.688 & $45,8 \%$ & 9.967 & $27,3 \%$ & 10.642 & $39,1 \%$ \\
\hline $\begin{array}{l}\text { Contra la } \\
\text { propiedad }\end{array}$ & 10.425 & $27 \%$ & 20.741 & $56,9 \%$ & 11.962 & $43,9 \%$ \\
\hline Total & 38.620 & & 36.475 & & 27.249 & \\
\hline
\end{tabular}

Fuente: elaboración propia a partir de las Estadísticas de Administración de Justicia en lo Criminal, recogidas de La Gaceta y de GIMENO AGIUS, 1885.

Entre 1843 y 1859 no contamos con estadísticas, y tampoco entre 1862 y 1883, por lo que no sabemos la evolución sostenida de los delitos en el conjunto del país. Entre 1859 y 1862 parece haber un pico, pero no conocemos si es la cumbre, y tampoco la inclinación de las laderas.

Ante la falta de datos en el ámbito nacional, en este artículo abordaremos el estudio cuantitativo y cualitativo del delito con fines lucrativos en Galicia a mediados del siglo XIX, para determinar si en esta región también se vivió un auge de los atentados contra la propiedad en el siglo XIX e intentar determinar por qué se produjo, cómo se interpretó en la época y de qué manera se reprimió. A este respecto, hemos dividido el capítulo en cinco apartados. En el primero explicaremos nuestras fuentes y método de estudio para evaluar las tendencias generales. En el segundo, desarrollaremos los datos proporcionados por esta aproximación cuantitativa y propondremos que los años de mayor aumento de los delitos contra la propiedad coincidieron con la crisis de subsistencias que se vivió en Galicia en los años 50 del novecientos. En el tercer capítulo, a partir de una cata de casos, veremos si se puede establecer una relación causal entre la crisis y el auge del robo, a partir del perfil de los autores. 
Finalmente, en el cuarto y quinto capítulo veremos de qué manera se perseguían y reprimían los delitos contra la propiedad.

\section{FUENTES Y METODOLOGÍA}

Para observar la evolución de los crímenes de naturaleza económica en términos anuales desde el establecimiento del sistema judicial liberal analizaremos las causas criminales instruidas por la Real Audiencia de Galicia que se conservan en el Archivo del Reino de Galicia, estudiando el periodo 1836-1864.

En primer lugar, ha habido importantes pérdidas de documentación. Se produjeron expurgos en 1847, 1849-1850, 1853, 1854, 1911 y en la posguerra ${ }^{5}$. Aun así, el archivo de las causas de la Real Audiencia supone la mayor colección de causas criminales para esta época en Galicia. En el Índice Topográfico Cronológico de Causas entre 1.836 y 1.864 encontramos unos 1.300 legajos de sumarios, lo que supone quizá unas 15.000 causas. A partir de este año solo se conserva documentación suelta, y libros-registro de sentencias a partir de 1873, según información facilitada por los responsables del archivo.

En segundo lugar, la Real Audiencia es un tribunal de apelación y control de la actividad de los órganos de partido. Determinados tipos de crímenes tienen más posibilidades de verse en la Audiencia y, quizás, de sobrevivir a los expurgos. Las causas por otros crímenes, como los asaltos en gavilla y los robos en iglesias, parecen haberse conservado sistemáticamente aunque solo sean sobreseimientos.

Finalmente, para realizar las estadísticas nos hemos basado en el ya citado Índice, un documento creado por el propio Archivo del Reino de Galicia en el que constan, además de los números que identifican el legajo y número de cada sumario, el partido judicial y año de origen y una breve descripción de la causa. Algunas causas, quizá unos pocos centenares, se conservan en los fondos del archivo pero no están incluidas en el Índice. Además, el documento contiene errores. En una muestra de 139 causas, sobre la que volveremos más adelante, hemos encontrado siete en las que la fecha se había transcrito mal (en seis de los casos el error era solo de un año), dos en las que se había cometido un error en el partido judicial del que provenían y dos en la que estaban mal ambos.

Para estudiar el comportamiento del crimen hemos seleccionado tres partidos judiciales de cada una de las provincias gallegas, buscando, en la medida de lo posible, la heterogeneidad social y económica. En la provincia de A Coruña se han elegido los partidos de Noia, Arzúa y Santiago de Compostela. En la de Lugo, Fonsagrada, Viveiro y Lugo. En la de Pontevedra, Cambados,

\footnotetext{
${ }^{5}$ LÓPEZ GÓMEZ, 1994, vol. 2: 914-920.
} 
Verín y Pontevedra. En la de Ourense, Xinzo de Limia, Valdeorras y Ourense. En todos se ha buscado un partido judicial con una ciudad con peso de la administración, otro con una villa costera (excepto, por supuesto, en Ourense, en el que hemos elegido uno que haga frontera con Portugal) y uno de interior. En cuanto al marco temporal, hemos escogido como años límite 1836, por ser el siguiente a la formación de los modernos partidos judiciales, y 1862, pues a partir de ese año el número de causas conservadas desciende de manera importante. En total, hemos registrado 3.733 causas.

GrÁFICo 2. Causas entendidas por la Real Audiencia

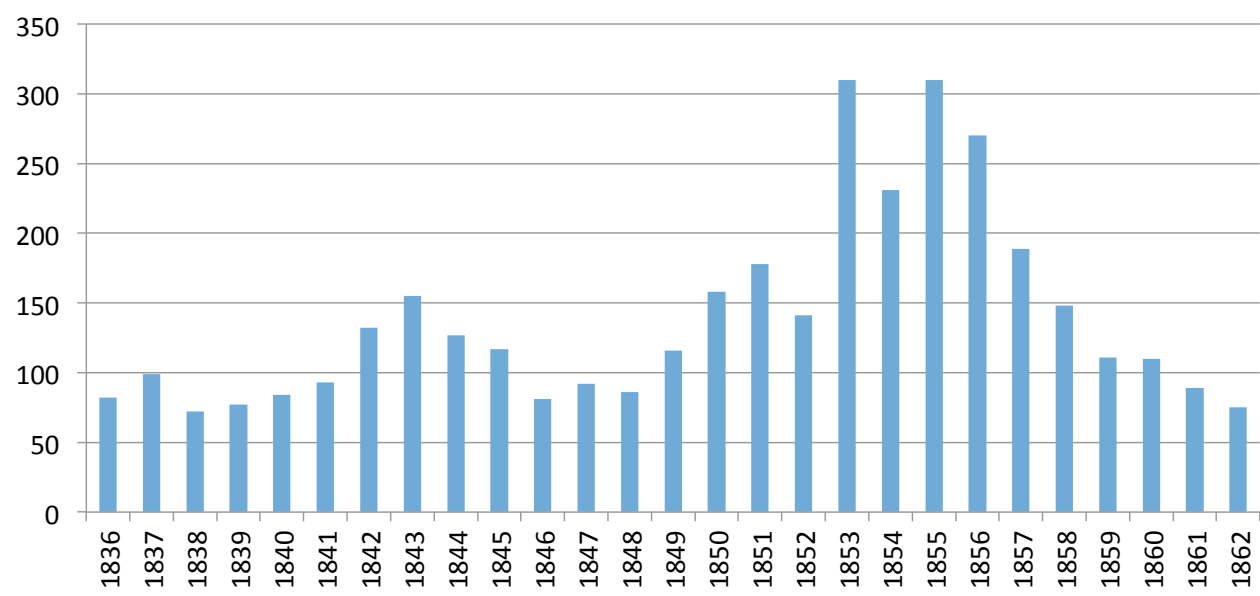

Fuente: elaboración propia.

\section{El PaUlatino Aumento del Delito económico y SU AUGe EN LA CRISIS DE SUBSISTENCIAS}

Para estudiar la evolución de la criminalidad, nos limitamos a los hurtos, robos y apropiaciones de bienes muebles (violentos o no), estafas, malversaciones, tráfico de mercancías ilícitas y moneda falsa, cobro de exacciones indebidas y defraudaciones. Incluimos las causas en las que el delito quedó en intento $\mathrm{y}$ aquellas en las que se persigue a sospechosos de ladrones, se aprehende a individuos con mercancías robadas o se actúa contra receptores, cómplices y encubridores. Son, en total, 1.651 casos. E1 97\% corresponden a robos y hurtos. Por comodidad, referiremos a ellos en el resto del capítulo como delitos económicos. Los datos indican que a lo largo del periodo hay un aumento de las causas vistas. 
GrÁfICo 3. Delitos económicos entendidos por la Audiencia

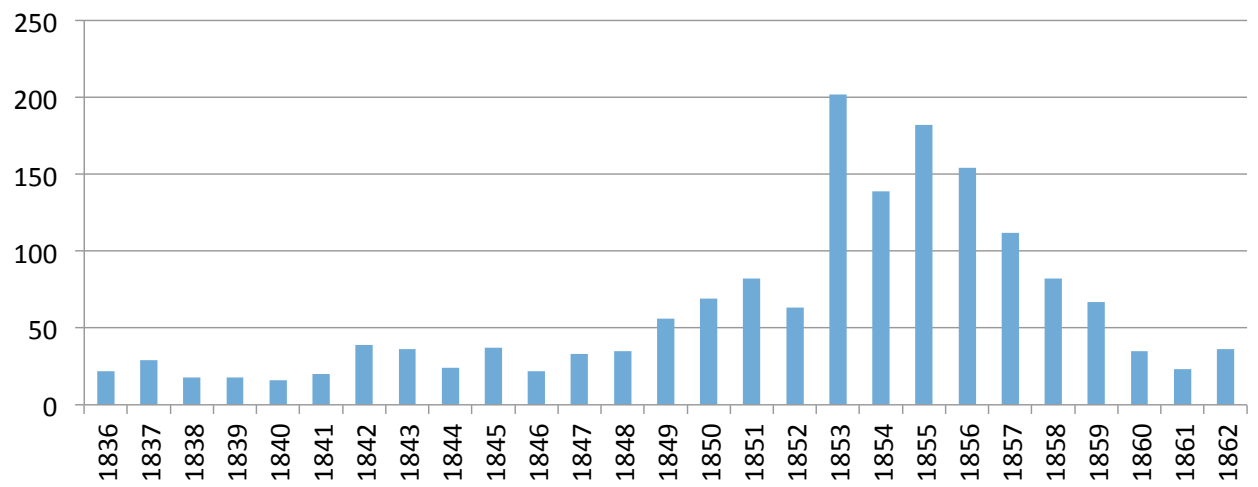

Fuente: elaboración propia a partir del Índice Topográfico Cronológico de Causas entre 1.836 y 1.864, ARG.

Al mismo tiempo, se produce un incremento relativo de los delitos económi$\cos$, que pasan de ser menos de un tercio del total a superar ampliamente el $50 \%$ en los años 50 .

Gráfico 4. Porcentaje de delitos económicos en relación al total

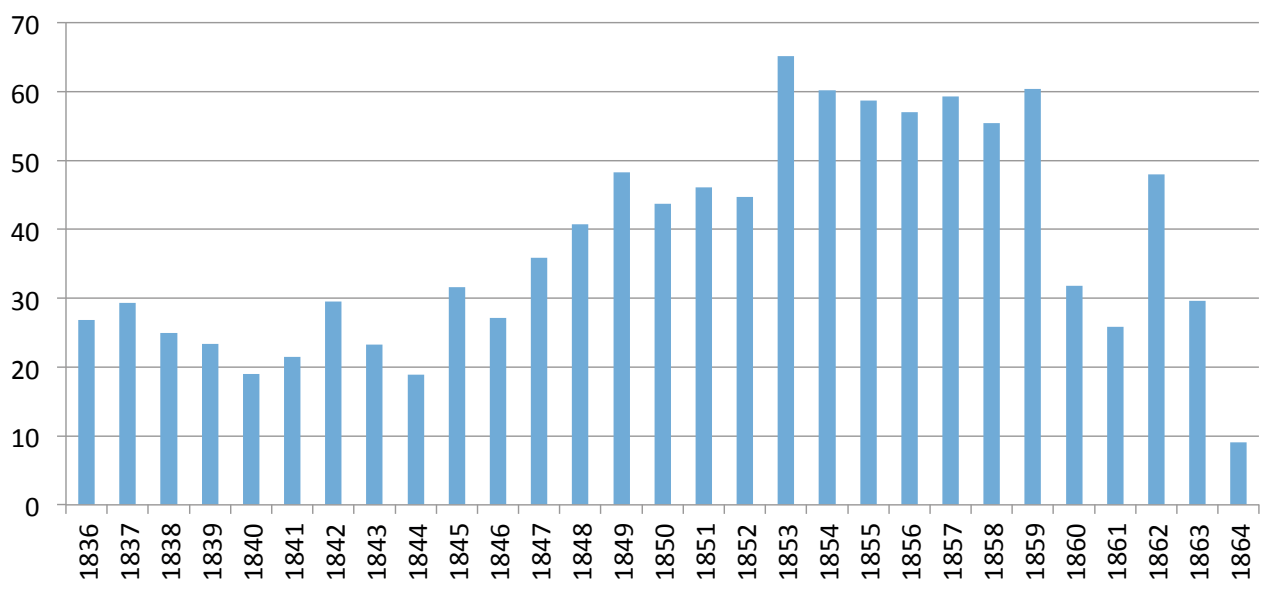

Fuente: elaboración propia a partir del Índice Topográfico Cronológico de Causas entre 1.836 y 1.864, ARG.

Entre 1836 y 1845 las causas por delitos económicos son minoritarias, entre algo menos de un quinto y algo menos de un tercio del total. En 1836 y 1837 el 
porcentaje de crímenes económicos es relativamente elevado en comparación con los años siguientes, pero aún así no llega al 30\%. La tendencia positiva se observa, quizás, ya en 1845, pero se hace evidente en términos relativos (no tanto en los absolutos) de 1847 en adelante. Entre 1848 y 1852 los delitos económicos ya suponen entre el 40 y el $50 \%$ del total todos los años. Si el incremento refleja un aumento real de la criminalidad, o de su persecución, tenderíamos a situarlo en la segunda mitad de la década de 1840. Simultáneamente se incrementa el número de causas.

El tercer periodo es el más claro. Entre 1853 y 1859 los delitos económicos ya son mayoría, entre el 54 y el $62,9 \%$ del total. En los años centrales de la década, 1853-1856, encontramos simultáneamente las cifras más altas de causas vistas por la Audiencia de todo el periodo y las tasas más altas de crimen económico en relación al total. En 1852-1853 hay un importante aumento de las aprehensiones por parte de la Guardia Civil en la provincia de A Coruña, y destacan las detenciones de ladrones en 1853 y de autores de faltas leves en 1852, lo que no deja de ser un indicador secundario pero relevante. Martínez Ruiz atribuye el aumento del crimen al hambre ${ }^{6}$. En cambio, el número de procesos se dispara en 1854, con un salto importante en relación a 1853. Esto puede deberse al expurgo ya mencionado de este último año, o a otros posteriores. En todo caso, la combinación de un alto número de causas con un porcentaje alto de delitos económicos lleva a pensar que se siguieron más procesos.

Las tasas más altas de crimen contra la propiedad se sitúan en los años de la crisis de subsistencias y los inmediatamente posteriores. Mientras que en la mayoría de países de Europa la crisis agrícola de mediados del XIX se produce en la segunda mitad de los años 40, en Galicia los peores años empiezan con la mala cosecha de 1852, en el que comienza una crisis de subsistencias que durará al menos hasta 1855 , si bien los precios del cereal no se normalizarán hasta la cosecha de 1857-18587. La crisis es, así, más larga que en el conjunto de España, que vive sus años de hambre en 1856-1857.

La relación entre un aumento de la criminalidad de tipo económico y el hambre en los años 50 ya ha sido señalada por parte de la historiografía para España ${ }^{8}$. En 1847, si bien se viven motines relacionados con el encarecimiento

${ }^{6}$ Señala que hay también picos de detenciones en Pontevedra y Lugo en 1852-1853 (no así en Ourense). Hay que apuntar, sin embargo, que el número máximo de detenciones en la primera provincia se da en 1857, y que el propio autor considera que el número de aprehensiones no refleja con fidelidad la criminalidad en algunos puntos de su obra. Sobre Galicia, MARTINEZ RUIZ, 1982: 97, 101-102, 105-108, 114, 146-147, 261-264.

7 RODRÍGUEZ GALDO y DOPICO, 1981: 15-19.

${ }^{8}$ Martínez Ruiz ve una «indudable» relación entre «los momentos de virulencia delictiva y los años de crisis económica y social» y afirma que «los años de crisis de subsistencias, pues, son años en los que los índices delictivos suben destacadamente». MARTÍNEZ RUIZ, 1982: 4, 11, 28, 32, 77. Según Gómez Bravo, en 1856, para Alcalá de Henares, «se sucedieron las 
del pan y cuestiones laborales y fiscales, y en Galicia, en particular, «the disturbances were at their most intense $\rangle^{9}$, no encontramos un aumento de la criminalidad. Esto no es extraño, ya que los motines suelen producirse en momentos puntuales ante la previsión del aumento de precios ( $\mathrm{y}$ en las villas y ciudades), y no en periodos de auténtica hambruna ${ }^{10}$.

En 1860 y los años subsiguientes los datos se hacen más escasos y la fuente pierde fiabilidad, sin embargo, parece que hay un patrón de descenso. Al menos en el partido judicial de A Coruña, el número de reos que ingresaron en la cárcel provincial condenados a arresto mayor por delitos económicos desciende a partir del pico de la segunda mitad de los años 50. Esta categoría incluye la mayoría de los hurtos y los robos menos graves, por lo que lo consideramos una fuente fiable para medir el delito económico menor.

GrÁfico 5. Reos de pena de arresto mayor por delitos contra la propiedad por 100.000 habitantes, en la cárcel de partido de A Coruña

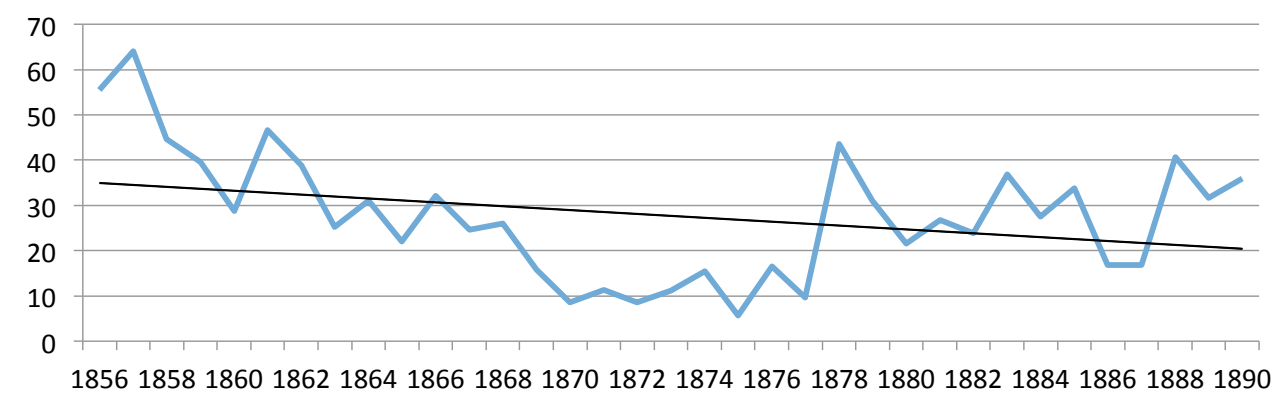

Fuente: registros de reos y censos ${ }^{11}$.

\section{«PARA Alimentar A SU MUJER y CUATRO hiJOS DE TIERNA EDAD». ESTRUC- TURA SOCIAL Y CRÍMENES POR HAMBRE DURANTE LAS CRISIS DE SUBSIS- TENCIAS}

Para determinar si podemos ligar el aumento aparente de la criminalidad económica en los años 50 a la crisis de subsistencias hemos realizado una cata

crisis del pan» y en paralelo el «hurto de alimentos y robo de cosechas». GÓMEZ BRAVO, 2004: 478, 525.

${ }^{9}$ Los encontramos en villas y ciudades: Vigo, Ponte Sampaio, Pontevedra, Santiago y A Coruña, donde se produjeron varios muertos por disparos de las tropas. DÍAZ MARÍN, 2007: 281.

${ }^{10}$ Según las tesis clásicas de Sorokin y Keys, citadas en VANHAUTE, PAPING y Ó GRÁDA, 2007: 38.

${ }^{11}$ Libro de reos de la cárcel pública de A Coruña, AMC, caja 5669. 
de las causas por robos y hurtos en los años 1844,1849 , 1854 y 1862 . Para obtener una visión amplia hemos dispersado la muestra en los diversos partidos judiciales, priorizando siempre los partidos capitalinos porque tienden a tener más causas criminales ${ }^{12}$, si bien no hemos encontrado causas suficientes para todos los años y todos los partidos ${ }^{13}$.

En total, hemos visto 139 sumarios, de los que hemos descartado 22 por mala clasificación, información mínima, mala conservación o porque la causa se desvió a otro partido. Los 115 restantes proporcionan un nivel de información muy heterogéneo. Hemos examinado las partes más ricas en información ${ }^{14}$, anotando sistemáticamente ciertos datos a los que se hará referencia más tarde.

En los tres primeros años de la muestra encontramos un par de casos de denuncias falsas que acaban en la persecución judicial de la parte demandante, pero la mayor parte de los sumarios acaban en condena para, al menos, un acusado. En concreto, hay 7,3 sumarios que acaban en condena por cada acusación. Por cada sobreseimiento se emiten 3,7 condenas. En 1862 la inmensa mayoría son sobreseimientos remitidos a la Audiencia para su aprobación y veredictos de libre absolución, y se incluyen una cantidad importante de denuncias maliciosas o apenas fundamentadas. Esto nos lleva a pensar que la muestra está sesgada; quizás estos años se eliminaron las causas más voluminosas. Este año, por tanto, queda excluido de los análisis que realizaremos a continuación, salvo cuando especifiquemos lo contrario.

Los datos apuntan a que parte del aumento de crímenes en la década de 1850 se debe al aumento de los delitos de subsistencia. En 1844 los delitos en los que se roba sobre todo alimentos son menos del 12\% de los crímenes, y en 1849 el 6,5\%. En 1854 suben al 34\%. En este año tenemos también un porcentaje significativo de sustracciones de enseres domésticos y herramientas

12 Se estableció como número a estudiar cuatro causas en 1844, 1849 y 1862 para cada uno de los partidos capitalinos, y dos para el resto. En 1854, en el que hay más datos, y tiene un plus de interés por ser el que nos puede dar más información de la crisis de subsistencias, el cupo fue respectivamente seis y tres, sumando 48. Se han observado por el orden en que aparecían en el listado del Archivo del Reino. Si una causa resultaba descartada, se pasaba a la siguiente, hasta agotar el cupo o el año.

13 En 1844 el número de causas observadas es de 17: cuatro en Lugo, una en Fonsagrada, ninguna en Viveiro, tres en Santiago, una en Arzúa, ninguna en Noia, una en Ourense, dos en Xinzo, una en Valdeorras, dos en Lalín, dos en Pontevedra y ninguna en Cambados. En 1849 se cumplió todo el cupo excepto en Xinzo, donde solo se vio una causa. En 1854 se cumplió todo el cupo menos en Fonsagrada, donde se encontraron dos. En 1862 se vieron 22: una en Cambados, dos en Pontevedra, dos en Lalín, tres en Lugo, ninguna en Fonsagrada, ninguna en Viveiro, dos en Santiago, dos en Noia, dos en Arzúa, cuatro en Ourense, dos en Xinzo y dos en Valdeorras.

${ }^{14}$ En particular, las sentencias en primera y segunda instancia, los relatorios de la causa, las indagatorias de los procesados, los informes del fiscal y los escritos de los acusados y sus abogados. 
(a veces acompañados de pequeñas cantidades de alimentos o ropa): suponen casi el 15\% de los casos, mientras que en 1844 eran el 5,9\% y en 1849 no hubo ninguno. Sumados, suponen casi la mitad de las causas examinadas ese año. Otro $10,6 \%$ son sustracciones de ropas y telas.

GRÁFICO 6. Sumarios acabados en condena, absolución y sobreseimiento según año

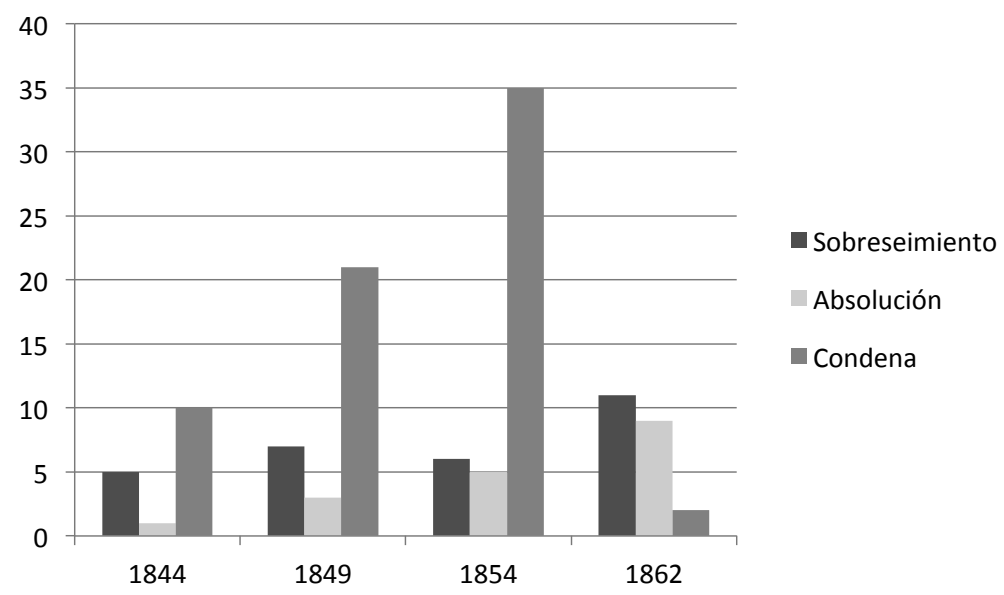

Fuente: elaboración propia a partir del Índice Topográfico Cronológico de Causas entre 1.836 y 1.864, $\mathrm{ARG}^{15}$.

No todas ellas son robos de supervivencia, y no todos los delitos de supervivencia son sustracciones de alimentos: los robos de ropas y telas son el 23,5\% de las causas en 1844 y el 32,3\% de las de 1849, y encontramos algún robo de alhajas justificado por el hambre. Pero el aumento numérico de los sumarios de robos de alimentos nos lleva a pensar que habían aumentado como estrategia de supervivencia en la crisis de los 50, o al menos se perseguían más.

Los pobres no siempre infringían la ley para cubrir una necesidad básica. José Villamarín, un sastre orensano de 22 años, le robó 60 reales a su madre en 1854

15 Hemos contado como acabados en condena aquellos sumarios en los que la Audiencia ratifica o establece una pena pecuniaria o de privación de libertad para, al menos, un acusado, en los casos en los que se conserva esta segunda instancia. Los sobreseimientos suelen representar denuncias en las que no hay sospechosos en firme, pero también incluyen casos en los que la persona contra la que se seguía el proceso murió o resultó exenta de responsabilidad criminal. Hay una situación en la que se confunden, hasta cierto punto, con las absoluciones, aunque no se hayan contado: contra algunos acusados se sobresee el proceso penal porque se determina que sus acciones fueron faltas o corresponden a la jurisdicción civil. 
porque aunque «le alimentaba y vestía, no le daba dinero más de alguna que otra vez para fumar y afeitarse y no para sus diversiones [sic]». Invirtió el dinero en emborracharse $^{16}$. Pero ese año, en el $12,8 \%$ de los casos, el procesado alega extrema miseria o la satisfacción de una necesidad urgente, o se reconoce así en el veredicto judicial. Otro 25,6\% apuntan en esa dirección (el encausado estaba pidiendo cuando cometió el crimen o admite ser un pordiosero, un testigo dice que lo hizo para comer aunque él no confiese el crimen, se hurtó leña para quemar). En 1849 hallamos este tipo de consideraciones en las defensas o en los veredictos en el $6,5 \%$ de los casos, y otro 6,5\% son dudosos, entre ellos un hombre que hurtó una yegua «acosado de necesidades y falto de medios con que atender á ellas [sic]», pero usó el dinero para comprar una vaca. En 1844 no lo encontramos en ninguno.

Gráfico 7. Distribución de los delincuentes por edad

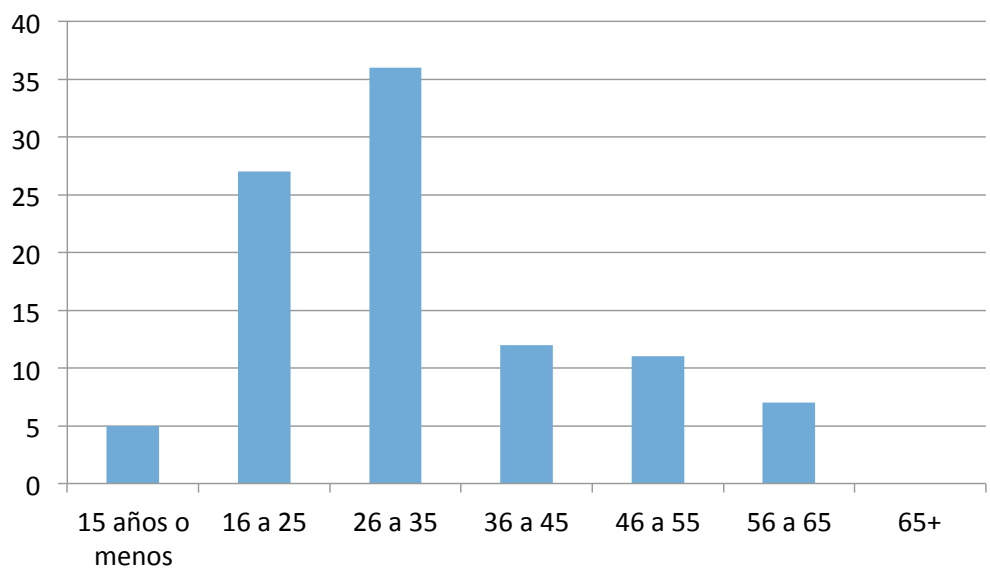

Fuente: elaboración propia a partir del Índice Topográfico Cronológico de Causas entre 1.836 y 1.864, ARG.

Pasemos a la estadística demográfica de los acusados, incorporando los casos de 1862 que resulten pertinentes. Excluyendo a los cómplices y encubridores, los casos de denuncias más infundadas ${ }^{17} \mathrm{y}$ un robo protagonizado por una nutrida banda de facciosos en 1844 del que tenemos poca información y que distorsionaría la estadística, encontramos a un total de 117 acusados. De ellos, los hombres suponen el 77,8\%. En los casos de subsistencia o dudosos,

\footnotetext{
16 ARG, Causas, caja 1746, expediente 3.

${ }_{17}$ Hemos entendido por tales aquellas en las que se condena al demandante, el caso se sobresee o el acusado es absuelto en primera y segunda instancia.
} 
son 20 de un total de 30 personas, esto es, el 66,7\%. En cambio, suponen el $100 \%$ de los casos en los que se produce algún tipo de violencia o intimidación grave contra las personas durante el robo. Esto encaja con otras observaciones sobre la delincuencia gallega en el siglo XIX. Las mujeres estaban más representadas en formas más leves de delito contra la propiedad, quizás como estrategia de supervivencia de mujeres marginales, pero apenas se encuentran en la delincuencia violenta grave ${ }^{18}$.

La distribución por edades señala un pico de la actividad delictiva entre los 16 y los 35 años, lo que no supone ninguna sorpresa. Los jóvenes y solteros delinquen más, y las cohortes demográficas que pasan la treintena empiezan a acusar el efecto acumulado de las defunciones:

Los crímenes de supervivencia y dudosos siguen el mismo patrón, pero mucho menos acusado, y un número comparativamente alto de mayores de 55 años participan en ellos. Como veremos más adelante, en esta franja se encuentran tanto pordioseros como trabajadores humildes que se ven sin medios para atender a sus familias por la crisis de 1854 .

GrÁFICo 8. Distribución de los delincuentes por edad en el crimen de supervivencia

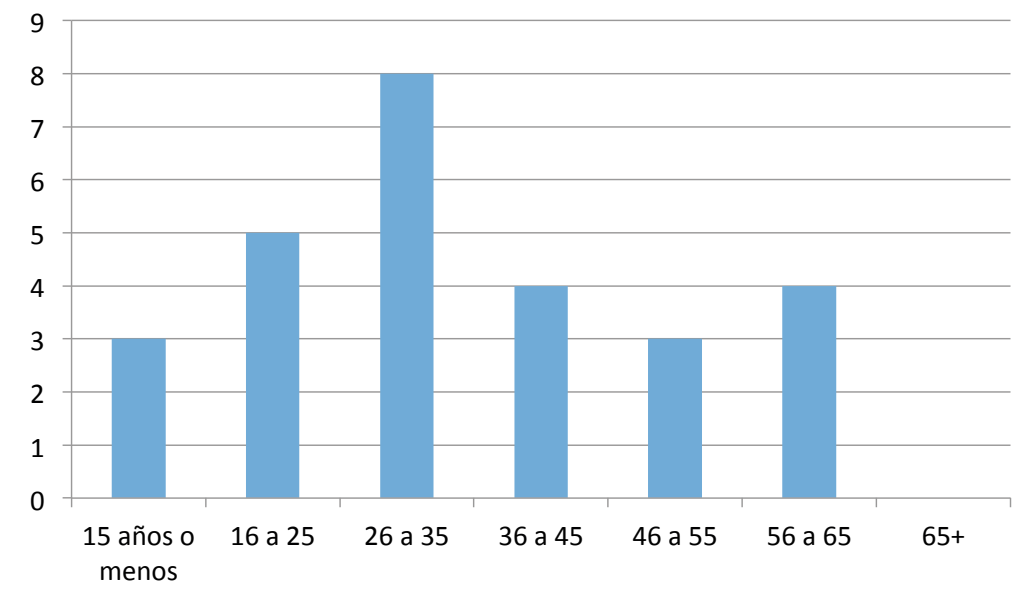

Fuente: elaboración propia a partir del Índice Topográfico Cronológico de Causas entre 1.836 y 1.864, ARG.

Se explicita la profesión de 98 encausados. El 43,9\% declaran trabajar en el campo, sin otra actividad. Los labradores suponen el $25,5 \%$, si bien el

\footnotetext{
${ }^{18}$ CARBALLO GENDE, 2018. IGLESIAS ESTEPA, 2004: 517, 691.
} 
término puede representar tanto a un mediano propietario con fincas que arrienda a terceros como a un casero o a un miembro del lumpen que tiene una choza y una pequeña huerta. La cantidad de insolvencias y el pequeño tamaño de los patrimonios que aparecen en los procesos de costas llevan a pensar que el perfil del criminal está más bien entre los últimos, y que muchos son jornaleros aunque no se definan así. Los explícitamente jornaleros, por su parte, suponen el $18,4 \%$.

El 27,6\% desempeñan profesiones artesanales, aunque algunos las complementan con labores agrícolas. Aproximadamente la mitad se dedican a tareas que requieren una formación o capital relativamente amplio, aunque algunos están arruinados. Entre el resto, tenemos tanto a aprendices adolescentes como a empleados en actividades más accesibles ${ }^{19}$. El 7,1\%, siete personas, son comerciantes. Cinco de ellas, todos hombres y de posición al parecer asentada, participaron en un robo en gavilla. Las otras dos son mujeres de estatus bajo: una regatona y una revendedora de pescado al por menor, que realizaron pequeños hurtos.

GRÁFICo 9. Distribución por profesiones de los acusados

\begin{tabular}{|l|c|c|}
\hline \multicolumn{1}{|c|}{ Profesiones } & Total & $\begin{array}{c}\text { Porcentaje de casos } \\
\text { en los que sí figura }\end{array}$ \\
\hline Labradores & 25 & 25,5 \\
\hline Jornaleros agrícolas & 18 & 18,4 \\
\hline Profesiones artesanales & 27 & 27,6 \\
\hline Comerciantes & 7 & 7,1 \\
\hline Mendigos o sin oficio conocido & 3 & 3,1 \\
\hline Menores de edad sin profesión & 4 & 4,1 \\
\hline Criados y sirvientes & 7 & 7,1 \\
\hline Profesiones letradas & 2 & 2 \\
\hline Otros & 5 & 5,1 \\
\hline Subtotal de aquellos de los que sabemos la profesión & 98 & 100 \\
\hline No figura & 18 & \multicolumn{1}{|c|}{} \\
\cline { 1 - 3 } &
\end{tabular}

Fuente: elaboración propia.

19 Para realizar el cálculo nos hemos basado en las observaciones de Domínguez Castro acerca de la distribución de las actividades artesanales en los estratos sociales del campesinado. DOMÍNGUEZ CASTRO, 2005: 466. 
El 4,1\% son menores de edad de los que no figura la profesión. Muy pocos, el $3,1 \%$, se describen como pordioseros o sin oficio: los pedigüeños suelen englobarse en las categorías de labradores o jornaleros, o se les asigna el último trabajo que realizaron. Los criados suponen el 7,1\% de los casos: en su mayoría están sin trabajo o han robado a sus amos. Encontramos también a un escribano (labrador y barbero a tiempo parcial) y a un trabajador de una contaduría, a los que hemos asignado una categoría aparte. Bajo el epígrafe «Otros» se engloban profesiones que solo aparecen una vez y que no encajan en las restantes categorías ${ }^{20}$.

En cuanto a los robos de subsistencia y los casos dudosos, hemos incluido la distribución por profesiones en la tabla siguiente, pero el tamaño de la muestra es demasiado escaso para sacar conclusiones fundadas. Aumenta el porcentaje de trabajadores agrícolas, ya que los casos que hemos visto provienen sobre todo del mundo rural. Los menores que aparecen, excepto en un caso, delinquen acompañados de sus padres o tutores.

GrÁfICO 10. Distribución por profesiones en los casos catalogados como crímenes de subsistencia o dudosos

\begin{tabular}{|l|c|c|}
\hline \multicolumn{1}{|c|}{ Profesiones } & Total & Porcentaje \\
\hline Labradores & 8 & 32 \\
\hline Jornaleros agrícolas & 5 & 20 \\
\hline Profesiones artesanales & 3 & 12 \\
\hline Comerciantes & 1 & 4 \\
\hline Mendigos o sin oficio conocido & 1 & 4 \\
\hline Menores de edad sin profesión & 4 & 16 \\
\hline Criados y sirvientes & 1 & 4 \\
\hline Profesiones letradas & 1 & 4 \\
\hline Otros & 25 & 4 \\
\hline Total & & 100 \\
\hline
\end{tabular}

Fuente: elaboración propia.

Los datos han de tomarse con reservas, pero nos muestran que el robo y el hurto son delitos típicos de las clases populares. No encontramos a miembros

${ }^{20}$ Un licenciado del ejército, un soldado, una mujer de profesión «labores de su casa», un peón y un minero.

Hispania, 2020, vol. LXXX, n. ${ }^{\circ} 264$, enero-abril, págs. 169-199, ISSN: 0018-2141, e-ISSN: 1988-8368 
de las clases altas entre los condenados por robos y hurtos. Sobre todo en el caso de los crímenes de subsistencias, parece concentrarse en los sectores más proletarizados y vulnerables a los vaivenes económicos.

Para entender las dinámicas sociales que llevaron al aumento del robo durante la crisis de subsistencias consideramos necesario un análisis cualitativo de ciertos casos. En 1854, vemos agricultores maduros sin antecedentes que se declaran labradores o jornaleros y que se ven incapaces de mantener a su familia. Según el abogado del labrador Manuel Canda, cuando su cliente entró en la noche del 30 de mayo de 1854 en un molino ajeno para extraer maíz (valorado en 39 reales) «el hambre le impulsara». Tenía 58 años, estaba viudo y tenía hijos. El robo no le sirvió de mucho: le encontraron el maíz la noche siguiente, y, fue condenado a un año de presidio. Murió el uno de enero de 1855 en la cárcel de Lalín ${ }^{21}$. Felipe Rodríguez, un jornalero de 60 años del partido de Valdeorras, fue encausado por hurtar a sus vecinos algunos haces de centeno y algunas patatas y garbanzos. Afirmó que «las mieses las ha cogido como [sic] el año está escaso de frutos para vivir a fin de tener algo más con que atender a sus necesidades $\rangle^{22}$.

Otro labrador de 44 años, José Sierra, robó un costal de maíz por valor de 12 reales del horno de una convecina. Antes de llegar a su casa lo sorprendió un hombre de la parroquia, Bernardino Doniz. Sierra, quizás derrumbándose ante los vecinos que se reunieron, confesó y entregó la llave con la que había cometido el hurto. Admitió los hechos ante el teniente de alcalde que llevó la instrucción, alegando solo que no tenía «cosa alguna que comer». La sentencia recoge que lo hizo «para alimentar a su mujer y cuatro hijos de tierna edad», resalta la «levedad del robo»y admite su «muy probable necesidad». Pero fue un robo con llave falsa, y, siguiendo el código penal, fue sentenciado a diecisiete meses de presidio correccional. Esquivó la prisión dándose a la fuga ${ }^{23}$.

Parece claro que estos robos derivan del empobrecimiento generado por la crisis, si bien no debemos pensar que afectó a toda la población por igual. Como hemos adelantado anteriormente, la sociedad rural gallega era heterogénea en cuanto a recursos y estrategias laborales y de supervivencia. Domínguez Castro engloba a los campesinos en tres bloques: aquellos que trabajan tierras propias, aquellos que trabajan tierras de otros (como jornaleros, y, también, los caseros en arrendamiento) y los pobres de solemni$\mathrm{dad}^{24}$. En este modelo caben todo tipo de gradaciones intermedias, y los linajes familiares y los individuos ascendían o descendían a lo largo del tiempo según su fortuna.

\footnotetext{
${ }^{21}$ ARG, Causas, caja 2150, expediente 5.

22 ARG, Causas, caja 1959, expediente 1.

23 ARG, Causas, caja 1746, expediente 13.

${ }^{24}$ DOMÍNGUEZ CASTRO, 2005: 465-469.
}

Hispania, 2020, vol. LXXX, n. ${ }^{\circ}$ 264, enero-abril, págs. 169-199, ISSN: 0018-2141, e-ISSN: 1988-8368 https://doi.org/10.3989/hispania.2020.006 
En relación a la crisis, podemos resumirlo en que existía un grupo que participaba en la economía rural más con su trabajo que con su capital: caseteiros, braceros, artesanos que suministraban productos de poco valor. Su contraparte serían los agricultores que trabajaban una cantidad significativa de tierra en propiedad o en modalidades de aparcería de larga duración o, incluso, arrendaban tierra sobrante. Los datos recogidos por Domínguez Martín a partir del censo de 1860 señalan que en torno a la mitad de la población activa agraria en Galicia se clasificaba como jornaleros agrícolas ${ }^{25}$. En esta denominación, repetimos, encajan muchas gradaciones: a mediados de siglo, una parte importante de los trabajadores gallegos en el agro dependían de vender su fuerza de trabajo y, quizás, se hubiese producido un empobrecimiento a lo largo de la mitad del siglo XIX debido a la alta presión demográfica y a la crisis de las actividades industriales.

En Europa, globalmente, el crecimiento de la producción agrícola no fue más rápido que el de la población entre 1750 y 1850, lo que generó polarización social y una clase de campesinos dependientes, para mantenerse, del trabajo ajeno ${ }^{26}$. La población gallega pasa entre 1787 y 1860 de poco más de 1,4 millones de habitantes a casi 1,8 millones, un incremento del $28 \%$. El ritmo de crecimiento es menor que el de la población española, pero la densidad de población gallega era más del doble que la del conjunto del país gracias al crecimiento entre 1650 y 1750 . En la década de 1820, estaba en el nivel de «las zonas más ricas de economía agrícola de Europa $»^{27}$. La consecuencia lógica, no por tópica menos cierta, era la «extremada división de la propiedad», como escribió en 1853 Castro Bolaño en el Informe sobre las causas de la Miseria [sic] en Galicia ${ }^{28}$.

Las tasas de crecimiento agrario en Galicia entre 1752 y 1900 son superiores a las del conjunto del reino de Castilla ${ }^{29}$, pero esto puede convivir con un empobrecimiento del campesinado. En Flandes, el aumento de la población generó empobrecimiento del campesinado pese al alto crecimiento de la producción, al elevarse el precio de la tierra y el monto de las rentas ${ }^{30}$. Cardesín, a partir de una observación en una parroquia rural del ayuntamiento de Castro de Rei, encuentra un incremento de la población de en torno al 40\% entre 1790 y mediados del siglo XIX, que coincide con un aumento de la producción intensiva y de la polarización económica ${ }^{31}$.

La práctica totalidad de la población participaba del trabajo o de las rentas del sector primario, complementado, entre las clases populares, con actividades

25 DOMÍNGUEZ MARTÍN, 1996.

26 VANHAUTE, PAPING y Ó GRÁDA, 2007: 18-19.

${ }^{27}$ DE JUANA LÓPEZ y VÁZQUEZ GONZÁLEZ, 2005: 394-400.

${ }^{28}$ Recogido en RODRÍGUEZ GALDO y DOPICO, 1981: 25.

${ }^{29}$ FERNÁNDEZ PRIETO, 2005: 144, en base a datos extraídos de SOTO FERNÁNDEZ, 2002

30 VANHAUTE, 2007: 125, 129-130.

31 CARDESÍN, 1992: 161, 165-166.

Hispania, 2020, vol. LXXX, n. ${ }^{\circ} 264$, enero-abril, págs. 169-199, ISSN: 0018-2141, e-ISSN: 1988-8368 
artesanales orientadas al mercado, entre las que destaca la industria casera del lienzo. Esta, sin embargo, entró en crisis en la mitad del siglo XIX, junto con las ferrerías y la producción de curtidos $^{32}$, y el cultivo de la vid, que tenía un papel fundamental en la economía de algunas zonas como Ribadavia, se vio afectado en la década de 1850 por la epidemia de oidium $^{33}$.

Vemos a algunos de estos pobres de aldea durante la crisis de 1854. Un ejemplo es Andrés Fernández, un labrador de 40 años de Vedra, soltero, que vivía en «dos alpendres o cobertizos» y, según sus propias palabras, se dedicaba a «cultibar sus cortísimos bienes y en trabajar al jornal cuando es llamado en casas de sus conbecinos pidiendo limosna cuando no tiene quien le llame [sic]». Su hermana y cuñado lo acusaron de robarles comida de su bien provista despensa. Fue arrestado e ingresó en la cárcel de Santiago en espera de juicio el 21 de febrero de 1854. De sus pertenencias al entrar en prisión solo tenemos esta frase: «ropa que trae, andrajos». Murió el 28 de febrero en el hospital ${ }^{34}$.

Para Gadd, el aumento de crímenes contra la propiedad se produce en años de malas cosechas en las que los altos precios del grano se conjugan con la falta de trabajo ${ }^{35}$. Quizás esto fue lo que vivió Ramón Lojo, alias Cuqueiro, al que encontramos en un proceso por robo de 1854. Era tan pobre que no tenía siquiera domicilio fijo, pero no era un marginal. La sentencia recoge que, según los testigos, era un hombre «laborioso» y «dedicado a los labores de la pesca, interín dura», y cuando esta cesa «al jornal que puedan darle de su trabajo en el campo, sin dejar nunca de trabajar» y «gozando de buena conducta». Se introdujo en un horno ajeno para robar un poco de pan de maíz, pero los propietarios lo atraparon. Lo achacó al «hambre». Tenía antecedentes de la década anterior (él decía que falsos), así que fue condenado a 36 meses de presidio correccional $^{36}$.

Incluso en los años buenos, la estrategia vital de este tipo de trabajadores dependía de la buena voluntad de su entorno, de los propietarios que les dieran trabajo y parte del sobrante de su producción, así como de obtener beneficios marginales de la explotación de los montes comunales que, en Galicia, se preservaron durante nuestro periodo de estudio ${ }^{37}$. Pero en la crisis los propietarios recortarían gastos, disminuyendo la demanda de trabajo externo, y seguramente eran más reticentes a la hora de compartir sus productos, necesarios para el autoconsumo y que alcanzaban precios altos en los mercados. No debemos restringir la demanda de trabajo externo a aquel por el que se pagaba un salario en dinero. El proletario agrícola podía recibir a cambio un pago en especie,

\footnotetext{
32 ALONSO ÁLVAREZ, 2005: 36-45.

33 RODRÍGUEZ GALDO y DOPICO, 1981: 119-135.

${ }^{34}$ ARG, Causas, caja 1434, expediente 2.

35 GADD, 2007: 330-331.

36 ARG, Causas, caja 1296, expediente 5.

${ }^{37}$ BALBOA LÓPEZ, 1990, especialmente: 53, 90-92, 156, 219-222.
} 
licencia para aprovechar el sobrante de la cosecha, el préstamo de animales o aperos agrícolas, etcétera. La privación de estas formas de aprovechamiento sería igualmente perjudicial, aunque no se expresase en términos monetarios, $\mathrm{y}$ el hecho de que fuesen irregulares y contingentes, por oposición a la contratación de criados y trabajadores por periodos largos de tiempo ${ }^{38}$, seguramente dificultaba que pudiesen reclamarse como un derecho.

Los estudios sobre la crisis de la segunda mitad de los años 40 en diversos países de Europa señalan a los pobres rurales como un colectivo perjudicado ${ }^{39}$, si bien en parte porque esta crisis afectó a la patata, un alimento del proletariado rural. Al mismo tiempo, otros trabajos señalan que los agricultores más solventes se veían beneficiados por el aumento de precios o participaban en la especulación ${ }^{40}$. La crisis de Crimea había provocado un aumento del precio del grano en toda Europa y, durante la crisis de subsistencias (sobre todo en 1855), se produjeron motines protagonizados por paisanos que intentan impedir la exportación de cereales ${ }^{41}$. Las dinámicas dependerían, quizás, del tipo de explotación y su nivel de acceso al mercado ${ }^{42}$.

\section{«SE VENDIERON TODOS SUS BIENES»: LAS DINÁMICAS DE REPRESIÓN DE DELITO MENOR}

Si al Sancionarse las Leyes que nos rigen hubiera pasado por un momento la idea a sus Legisladores de que algunas Provincias de Galicia habían de pasar por los azares que hemos presenciado indudablemente hubieran formulado un Código especial que penara estos delitos escepcionales e hijos de las circunstancias [sic].

Son las palabras del abogado de Antonio Espantoso, un joven zoquiero (fabricante de zuecos) de Arzúa encausado por robar telas, ropa y comida de un almacén por «la estrema [sic] hambre y miseria», y «una de las víctimas en

${ }^{38}$ En Dinamarca, el elevado número de trabajadores que percibían bienes en especie pudo ayudar a mantener la estabilidad durante la crisis de la segunda mitad de los años 40. HENRIKSEN, 2007: 311.

39 Así ocurre en Irlanda, donde se multiplican los desahucios de familias pobres (DALY, 2007: 65-66); en Francia, donde los pequeños propietarios y los pobres tuvieron que recurrir al crédito para alimentarse, (VIVIER, 2007: 231-232); y en Dinamarca a mucha menor escala (HENRIKSEN, 2007: 308).

${ }^{40}$ Así ocurre, por ejemplo, en el sur de Alemania, donde «there was a marked contrast in fortunes between the lower classes, on the one hand, and the farmers, who could sell their crops at a price that more than made up for the decline in yield, on the other», MAHLERWEIN, 2007: 217-218. También encontramos dinámicas de ese tipo en Holanda, PAPING y TASSENAAR, 2007: 165, 171.

${ }^{41}$ RODRÍGUEZ GALDO y DOPICO, 1981: 29.

42 BASS, 2007: 199-200. 
quien ha hecho tantos estragos el hambre y miseria que ha afligido a este Partido». Gregorio María García, juez de primera instancia de Arzúa y alcalde segundo, no tuvo en cuenta este alegato, y lo condenó a treinta meses de presidio (reducidos, tras apelar, a diecisiete) ${ }^{43}$.

Para entender en todas sus dimensiones el modo en el que el sistema penal castigaba al preso no debemos atender tan solo a los meses o años de prisión a los que se condena, sino a la situación del preso durante el proceso judicial y después de la sentencia.

En primer lugar, como nos enseña el ejemplo ya citado de Espantoso, se castigaba a los delincuentes independientemente de los motivos que les hubiesen impulsado a robar; como mucho, estos podían aliviar la condena. En este sentido debemos distinguir dos periodos. Hasta 1848, salvando el breve paréntesis del Código Penal de 1822, los jueces se rigen por la Novísima Recopilación de las Leyes de España. Las penas que se imponen en caso de hurto son arbitrarias, según la valoración que el juez haga de «la repetición o reincidencia, el valor de lo que se regulare el robo, la calidad de la persona á quien se robó, y la del delinqüente, con lo demás que se halla prevenido por el Derecho[sic] $\rangle^{44}$. Es posible que algunos jueces incluyesen la necesidad entre estas circunstancias, aunque no hemos visto casos.

En el Código Penal de 1848, y su actualización de 1850, los periodos de pena quedan establecidos por ley y con ellos la lista de circunstancias atenuantes, agravantes y eximentes. Entre ellos no se encuentra el hambre o la satisfacción de necesidades básicas, si bien se exime de pena al que «obra violentado por una fuerza irresistible» ${ }^{45}$ y se atenúa la pena al que lo hace por estímulos «poderosos» ${ }^{46}$ y circunstancias análogas. En los casos que hemos visto, los jueces nunca consideran el hambre un eximente, y en la mayoría de las sentencias de 1854 ni se menciona.

Sí que hemos identificado algunos casos en los que se tiene en cuenta como atenuante. La Audiencia impuso una pena mínima de un mes de arresto mayor a María López y a María Antonia Veiga, que hurtaron un cabrito y un cordero en 1849, y mandó que, en atención a las «miserables circunstancias que concurren en las procesadas y la tenacidad [sic] del delito perseguido», se «sobresea en mas [sic] actuaciones», lo que lleva a pensar que el juzgado de primera instancia había impuesto otras cargas (aunque no hemos encontrado esta sentencia $^{47}$. En 1862 hay otros dos casos: el de Josefa Arce, una pordiosera que se

43 ARG, Causas, caja 1048, expediente 11.

${ }^{44}$ Así se decretó en 1745 y figura en la Ley VI del Libro XII, Título XIV, de la Novísima Recopilación de las Leyes de España.

${ }_{45}$ Código Penal de 1850, art. 8.9

46 Código Penal de 1850, art. 9.7.

${ }^{47}$ ARG, Causas, caja 1476, expediente 7.

Hispania, 2020, vol. LXXX, n. ${ }^{\circ}$ 264, enero-abril, págs. 169-199, ISSN: 0018-2141, e-ISSN: 1988-8368 https://doi.org/10.3989/hispania.2020.006 
llevó cinco racimos de uvas de un campo «para comer con un poco de pan» ${ }^{48}$, y el de Manuela Piñeiro, que hurtó ropas a una mujer que la había acogido, según su propia declaración, por «el hambre que padecía y siendo joven que no podía mendigar». Aquí encontramos declaraciones favorables tanto del fiscal, para el que actuó «impelida por la necesidad que la rodeaba, circunstancia que atenúa su responsabilidad», como del juez, que considera que actuó «sinó [sic] en todo alo [sic] menos en parte por el poderoso estimulo del hambre» ${ }^{49}$.

Quizás las actitudes hacia el robo se hubiesen dulcificado fuera del periodo de la crisis de subsistencias, quizás las condenas hacia mujeres fuesen un poco más leves. Pero, en todos estos casos, las acusadas entraron en la cárcel. Durante nuestro periodo de estudio todas las sustracciones por mínimas que fuesen, exceptuando unos pocos casos muy concretos ${ }^{50}$, se penaban con un mínimo de un mes de cárcel.

El segundo punto a tener en cuenta es que los acusados pasaban una cantidad variable de tiempo arrestados en la cárcel a espera de juicio. De hecho, en algunos crímenes menores acababa englobando la pena de cárcel: en los años 40 vemos cómo en algunas sentencias se especifica que las penas se entienden contadas «desde el dia[sic] en que fueron constituidos en prisión [sic] $»^{51}$, y en otras se condena «a la Prision [sic] Sufrida y un mes Mas[sic] de Carcel[sic] $\rangle^{52}$. En el ámbito español, el 9,7\% de las sentencias en 1843 eran de «prisión sufrida $\rangle^{53}$. En 1853 y a partir de entonces, cada dos días de arresto se abonarán por uno de sentencia.

El arresto era una experiencia desagradable por las malas condiciones de las prisiones, y porque en las cárceles de partido se mezclaban acusados y condenados de todo tipo. Pero, más importante, era ruinoso. Además de perder días de jornal, los detenidos debían ocuparse de su propia manutención. Josefa Santa María, una costurera de 26 años de Boiro, entró en 1854 en la cárcel de Noia acusada de hurtar carne de cerdo a un vecino. Su marido trabajaba desde el amanecer hasta la noche como atador en un almacén, tenían dos hijos menores de tres años, así que, para mantenerse en la cárcel, solicitó alimentos por ser pobre. Sin embargo, en el informe de pobreza apareció como propietaria de "una casita, una heredad de una conca de sembradura, y un pedacito de viña». Pasado el informe al promotor, determinó que se subastasen las propiedades y que Santa María se mantuviese con el fruto de la venta. En el informe del perito

\footnotetext{
48 ARG, Causas, caja 1774, expediente 10.

49 ARG, Causas, caja 2096, expediente 9.

50 Se consideraban faltas la entrada de ganado y la tala de leña en una finca ajena, la recogida de espigas y otros restos de cosechas y entrar en una finca «para coger frutos y comerlos en el acto». Código Penal de 1850, artículos 495.21, 495.23, 496, 497, 499.

${ }^{51}$ ARG, Causas, caja 2143, expediente 1.

52 ARG, Causas, caja 2019, expediente 12.

53 Gaceta de Madrid, 14-02-1845: 1-2.
} 
podemos comprobar que la casa solo la poseía a medias, y era «una pequeña choza sin apartados ni divisiones y solo la cubre un mal techo» ${ }^{54}$. El conjunto de las propiedades se tasó en 114 reales. En otro sumario vemos cómo todas las propiedades del platero José Leiva son embargadas y vendidas «para pagar el importe de socorro al mismo suministrado durante su prisión $\rangle^{55}$.

Los presos insolventes tenían en teoría derecho a la alimentación gratuita, pero, en la práctica, se formaba un mercado negro para cubrir necesidades básicas. Leemos en la declaración de un preso de la cárcel de Lalín: «Haberá como cosa de dos meses poco mas o menos y en época que el deponente se hallaba asentado en la cárcel de este Partido vino tambien a ella un tal Juan Carro, y como se hallase necesitado y no tubiese cosa alguna que come el mismo deponente le fue adelantando algunas libras de Pan para su sustento, y por cuia satisfacción el Carro le dio unos Borciguies ya usados de Cuero [robados], que como nole veniesen bien al declarante y le lastimasen los pies, tubo que volverlos a vender aun sugeto desconocido que allí vino por la Carcelen la cantidad de trece reales [sic] 1$\rangle^{56}$.

Los juicios eran relativamente rápidos, y las condenas por hurtos simples podían reducirse a algunos días de prisión. Pero se presentaba un castigo adicional para los más pobres: afrontar los gastos del juicio, desproporcionados en relación a lo robado. «Por más que á primera vista parezca como una cosa insignificante el arresto de ocho días á que han sido condenadas mis defendidas, hay una consideración que da grande importancia á lo que parece no tenerlo. Tal es la condenatoria de costas y gastos del juicio que se imponen á las encausadas [...]. Resulta de aqui que lo que para otras personas de mas fortuna seria una cosa de poca importancia, para Marta y Pascua Varela es de grande consideración; pues al fin se [t]rata de una pena que ha de tener para ellas los mismos resultados que si se confiscasen todos sus bienes [sic]», alega el abogado de dos hermanas condenadas por hacerse con unos pocos manojos de centeno. Efectivamente, el proceso de costas se prolongó hasta 1857, y el embargo de los bienes de las mujeres no alcanzó para satisfacer el monto ${ }^{57}$.

Esta carga recaía también sobre los que no eran condenados pero tampoco lograban demostrar del todo su inocencia. En el caso de Josefa Santa María, de la que ya hemos hablado, leemos en una comunicación del fiscal que «el ministerio imparcial solo puede, solo debe pedir al Juzgado que se sirva absolver de la instancia a Josefa Santa María si bien condenándola en las costas y gastos del juicio al tenor de lo que dispone el artículo cuarenta y seis del Código penal en atención a los vehementes y graves indicios que contra ella resultan».

\footnotetext{
${ }^{54}$ ARG, Causas, caja 1296, expediente 3.

ARG, Causas, caja 1724, expediente 16.

ARG, Causas, caja 2020, expediente 8.

57 ARG, Causas, caja 2021, expediente 10.
}

Hispania, 2020, vol. LXXX, n. ${ }^{\circ}$ 264, enero-abril, págs. 169-199, ISSN: 0018-2141, e-ISSN: 1988-8368 https://doi.org/10.3989/hispania.2020.006 
María Alverta González y su yerno Pedro Gómez resultaron absueltos de robo de maíz en 1854, y solo tuvieron que afrontar las costas de su defensa. Los bienes de ambos fueron subastados y se reunieron 1.481 reales; la deuda era de 2.220. En la práctica, se arruinaron ${ }^{58}$. Ya hemos visto el caso de Ramón Lojo, cuyo delito fue intentar apoderarse de un pan que, según su abogado, no valía más que cuatro reales. Las costas y gastos del juicio ascendieron a 790. Él, por lo menos, era insolvente, con lo que se le perdonaron las costas. Por los gastos del juicio y el pago de multas e indemnizaciones, sin embargo, los insolventes tenían que cumplir más tiempo de cárcel, un día por cada medio duro impagado ${ }^{59}$.

Un caso extremo es el de Ángel Luna, un labrador de 50 años de Canedo que robó algunas cepas «que consideró infructíferas con el objeto de venderlas para comprar una libra de pan y quemar algunas para calentar a su familia». A nivel penal, salió bien librado. El ofendido le perdonó la indemnización (las cepas valían diez reales) y no cumplió el mes de arresto que se le impuso porque pudo acogerse al indulto del 22 de enero de 1854 . Pero todos sus bienes se pusieron en subasta para pagar los gastos del juicio. La causa para determinar si era insolvente o le quedaba algo por embargar continuó, al menos, hasta $1862^{60}$.

Manuel Varela, un labrador de Buján, pasó un año en la cárcel de Santiago en 1842, cuando tenía unos treinta años, por robar en un molino. En una sentencia que recibió ocho años después, se recoge que en aquella ocasión «se le vendieron todos sus bienes sin que actualmente tenga algunos ni de que [sic] vivir». En 1854 lo encontramos viviendo del robo: «hecha [sic] la mano a todo lo que puede ${ }^{61}$. En su caso, todos sus vecinos lo consideraban un maleante, así que quizás hubiese vuelto al crimen de cualquier manera. Pero no todos los afectados por los procesos penales eran así. En las indagaciones del juzgado de Cambados para averiguar la solvencia de José Antonio Cores leemos que «ha sido siempre un zapatero remendón sin casa ni hacienda propia alguna, y que desde que se vendió la casa terrena perteneciente a su mujer para pago de costas en que fue penada por el Tribunal superior por causa contra ella formada, anda aquel pordioseando por la provincia [sic]». En 1854 volvió a su parroquia, donde debía tener aún una choza o algún refugio, y cortó alguna leña para calentarse en la propiedad de un vecino. Este dio parte a la alcaldía y Cores acabó en la cárcel ${ }^{62}$.

Encontramos a alguna gente que no quiere denunciar «por no entrar en gastos» ${ }^{63}$, pero los robos y los hurtos eran delitos públicos y la justicia seguía las

\footnotetext{
${ }^{58}$ ARG, Causas, caja 2027, expediente 4.

${ }^{59}$ Código Penal de 1850, artículos 48 y 49.

${ }^{60}$ ARG, Causas, caja 1747, expediente 2.

${ }^{61}$ ARG, Causas, caja 1748, expediente 8.

${ }^{62}$ ARG, Causas, caja 2086, expediente 13.

${ }^{63}$ ARG, Causas, caja 1476, expediente 8.
}

Hispania, 2020, vol. LXXX, n. ${ }^{\circ} 264$, enero-abril, págs. 169-199, ISSN: 0018-2141, e-ISSN: 1988-8368 https://doi.org/10.3989/hispania.2020.006 
denuncias de oficio, de manera que el denunciante solo tenía que acudir a la autoridad. Los denunciantes ni siquiera tenían por qué ser parte en el juicio, y algunos, por ejemplo, renunciaban a cobrar indemnización, pero otros acusaban de robo a amantes huidos o vecinos con los que tenían problemas personales $^{64}$, o empleaban la vía penal, y no la civil, para solventar cuestiones de propiedad.

Había colectivos a los que lo oneroso de los castigos no servía de inhibición. En los robos en gavilla y los crímenes con violencia e intimidación encontramos tanto a delincuentes endurecidos como a otros sin antecedentes, pero que tienen perspectivas de conseguir sumas importantes de dinero. En el caso de los hurtos de poca cuantía, había gente que tenía poco que perder o que no sabía vivir de otra forma. María Juana Fernández, mujer «incorregible, vagante entregada a sus vicios», fue detenida en 1849 por sospechas de robo, pero mientras la conducían a Vilalba se fugó de un domicilio particular donde había hecho noche (llevándose de paso unos zapatos). La dejaron dormir de limosna en una casa y también hurtó allí. Según su propia declaración, ya había estado en la cárcel por robo, por la desaparición de una niña y por agredir a un hombre. Murió bajo arresto por una «afeccion enomica [sic] del pecho sostenida por un antiguo vicio sifilítico» ${ }^{65}$.

Un colectivo que quizás recurriera al robo para complementar sus ingresos era el de los núcleos familiares formados por mujeres sin tierras ni oportunidades laborales remuneradoras. En especial, puede que fuese especialmente frecuente entre las jornaleras y pordioseras con hijos de soltera, un caso en el que el crimen pudo ser una estrategia heredada de madres a hijas. Benita Graña, de quince años, fue arrestada en 1854 por robar pendientes de escaso valor en una joyería de Pontevedra. Había entrado en la ciudad acompañada de su madre, Rosa Graña (que también era hija natural), y María Benita Giménez. Ambas habían sido condenadas por otros robos. El abogado de la segunda achacó el crimen a «la miseria, la espantosa miseria que pesava [sic] sobre la procesada y sus hijas» ${ }^{66}$. Creemos que los delitos de este colectivo no están ligados de manera tan clara a la crisis de 1854, sino a una situación de pobreza y exclusión social sostenidas.

Otro caso es el de las mujeres de la familia Vidal, de Pontevedra, a las que no se les conoce «bienes algunos pues son unas semi-pordioseras que viven de lo que pueden agenciar con el sudor de su [incomprensible] y de caridad $\rangle^{67}, \mathrm{o}$ Manuela Fernández y su hija natural Benita, de Dozón, detenidas por robos en 1844 cuando ya ambas eran reincidentes. Estos linajes de solteras parecen

\footnotetext{
${ }^{64}$ ARG, Causas, caja 2049, expediente 19.

65 ARG, Causas, caja 1476, expediente 8.

${ }^{66}$ ARG, Causas, caja 2027, expediente 2.

67 ARG, Causas, caja 2027, expediente 10.
}

Hispania, 2020, vol. LXXX, n. ${ }^{\circ}$ 264, enero-abril, págs. 169-199, ISSN: 0018-2141, e-ISSN: 1988-8368 https://doi.org/10.3989/hispania.2020.006 
encontrarse con más frecuencia entre los delincuentes de Pontevedra, seguramente porque había más mujeres en esa situación ${ }^{68}$.

También encontramos algún delincuente precoz entre los jóvenes de familias desestructuradas. Manuel Cabanelas, pontevedrés acusado de robar dinero, fue detenido mientras andaba pidiendo «por cuanto su madre y padrastro no lo cuidan ni nada le dan». Había enseñado su botín para comprar algo de ropa, que enseñó a un compañero suyo y de allí se fueron «a hechar [sic] un vaso de vino en una taberna» ${ }^{69}$. Tenía doce años.

\section{VECINOS LADRONES, VECINOS DELATORES: LA PERSECUCIÓN DEL CRIMEN}

Parece intuitivo que en periodos de absoluta desesperación aumenten los robos simplemente para sobrevivir. En la Irlanda de 1847, en plena hambruna de la patata, el crimen se triplicó, en especial el económico y, al parecer, había gente que delinquía con tal de entrar en prisión y asegurarse algo de comida ${ }^{70}$. En lugares que sufrieron crisis menos violentas la explicación quizás sea más compleja. En Bélgica el número de juicios en los tribunales correccionales aumentó un 50\% en 1847, por un aumento de delitos ligados a la crisis de ese año, pero también por la represión: «afin de garantir l'ordre public, une répression tous azimuts des vagabonds et mendiants est donc décrétée dès les premiers signes de la crise» ${ }^{71}$. En Flandes aumentó el crimen, pero también la cantidad de estatutos de policía, la persecución de mendigos, o las rondas para expulsar vagabundos ${ }^{72}$.

En Galicia pudo haber alguna actuación formal dirigida a reprimir el crimen, al menos en el ámbito local ${ }^{73}$. Pero si atendemos al conjunto de causas, incluyendo las de 1862 , observamos que solo en un 3,4\% de las ocasiones el aviso del crimen lo da una autoridad (un guardia, o, en una ocasión, el alcalde). En el $76 \%$ de las ocasiones, con seguridad, y en otro $16,2 \%$ con más dudas, el aviso lo da un miembro de la sociedad civil, normalmente el propietario o un allegado, más raramente un testigo, y en alguna ocasión un pedáneo o un compañero de celda. En el restante $5,1 \%$ de casos la persona que identifica el robo es dudosa o corresponde a tipologías marginales.

68 SAAVEDRA FERNÁNDEZ, 1992.

${ }^{69}$ ARG, Causas, caja 2021, expediente 5.

70 Ó GRÁDA, 2007: 47.

71 VESENTINI, 11/1 (Ginebra, 2007).

72 VANHAUTE, 2007: 136-139.

${ }^{73}$ Parece que en 1856 el ayuntamiento de Ribadavia creó tres plazas de policía «a fin de evitar los diferentes robos que nocturnamente se cometen, asaltando las casas de los vecinos indefensos, consecuencia de la espantosa miseria que estaban pasando todas las clases». Recogido por Samuel Eiján (Ribadavia y sus alrededores, Madrid, 1920: 597-598), citado en RODRÍGUEZ GALDO y DOPICO, 1981: 122. 
En nuestra opinión, existió una persecución voluntaria por parte de los vecinos, y no únicamente por la imposición del Estado ${ }^{74}$, del crimen contra la propiedad. Obviamente, los individuos que más se implican en la persecución de los delitos son los perjudicados, que en una sociedad en la que la implantación de las fuerzas policiales era todavía débil debían moverse si querían perseguir el crimen $^{75}$. Existe un complejo mundo de prácticas consuetudinarias y relaciones sociales y económicas en el que no entraremos, por falta de espacio y de fuentes adecuadas, y que establecía un marco de tolerancia para algunos crímenes contra la propiedad. Puntualmente, encontramos individuos que toleran, al menos durante algún tiempo, los delitos de sus vecinos, o los intentan reconvenir. Pero también encontramos a paisanos que detienen e interrogan a foráneos que les parecen sospechosos, paran a vecinos que llevan frutos que, a su juicio, no deberían tener, o señalan a miembros de su comunidad como sospechosos de robo. Creemos que el hurto y el robo eran vistos con más hostilidad por la masa de la población gallega de mediados del siglo XIX que otros crímenes contra la propiedad. En concreto, que aquellos que no les perjudicaban directamente, como el contrabando ${ }^{76} \mathrm{o}$ el aprovechamiento de montes públicos ${ }^{77}$.

En un $10,2 \%$ de los casos, el hecho se lleva directamente al juzgado, y en el $29 \%$, a fuerzas de policía formales (guardias civiles, agentes de vigilancia, carabineros, serenos), a veces porque el denunciante los busca, a veces porque están cerca del lugar del robo. En una parte de estos casos, los paisanos acuden después de haber realizado indagaciones o arrestan a los sospechosos ante el juez $^{78}$. Hallamos otro $10,3 \%$ de casos en los que el proceso es desconocido o pasa a través de autoridades minoritarias, como el alcaide de una prisión, el gobernador civil, el jefe político, el promotor fiscal o la Milicia Nacional.

Pero las fuerzas de la administración local son aún más importantes, y a ellas se recurre en aproximadamente la mitad de los casos. En un 19,7\% de las ocasiones, la primera autoridad que conoce los hechos es el alcalde. En el $30,8 \%$ de las ocasiones, el acusador habla con el pedáneo, el alcalde de barrio, el celador del lugar o un cargo equivalente.

${ }^{74}$ Los testigos que, a colación de un juicio, mencionan que el acusado hurtó con anterioridad y que no lo denunciaron no son perseguidos.

75 En las colonias norteamericanas, el sheriff era «a reactive agent. He acted upon a formal complaint or information about an offense. The initiative lay with the public», WALKER, 1980: 18.

${ }^{76}$ Que a finales del Antiguo Régimen era tanto un modo de supervivencia para comunidades marginales como un oficio lucrativo en el que estaban implicadas partes de las clases privilegiadas, MELÓN JIMÉNEZ, 2009: 392-393.

77 El impago de las tasas por aprovechamiento fue generalizado en Galicia, BALBOA LÓPEZ, 1990: 219-222.

${ }^{78}$ Por ejemplo, en ARG, Causas, caja 1556, expediente 4. 
El recurso a la justicia varía según dónde se realice el delito. En los casos que se producen en los cascos urbanos de Pontevedra, Lugo, Ourense y Pontevedra, el $73,7 \%$ de los casos pasan por el juzgado o las fuerzas policiales, lo que no es de extrañar ya que están físicamente más próximos al denunciante. Solo el $21 \%$ pasa por alcaldes y pedáneos. Pero fuera de las ciudades el patrón se invierte. El 55,7\% de los casos llegan primero a alcaldes y pedáneos, y el 33\% a jueces y policías. La preferencia por la autoridad municipal y sus delegados en el mundo rural probablemente se explique, en parte, porque eran las que más poder tenían sobre sus vidas a través de las redes caciquiles. Pero, sobre todo, eran los más cercanos. En un caso en Curtis, el alcalde, la corporación municipal y varios pedáneos interrumpieron una reunión en la casa consistorial para defender a un sacerdote de la localidad, cuya casa estaba siendo asaltada por una gavilla de ladrones; estos desistieron y se marcharon «disparando tiros a todos costados [sic] $\rangle^{79}$.

No todos los pedáneos muestran la misma diligencia. Algunos se limitan a dar parte verbal o escrita al alcalde. Pero otros reúnen testigos y declaraciones, gestionan arrestos, o registran, acompañados por algunos vecinos, casas y terrenos en los que pueden estar guardados productos robados, quizás de manera no muy legal. Un celador orensano llegó a comparar las huellas dejadas en el lugar del crimen con el calzado de los sospechosos ${ }^{80}$. Actúan en compañía de los denunciantes o con vecinos que reclutan en el momento. «Halle [sic]a la persona de Pedro Bernardez lo lleve en mi auxilio» y, un poco más adelante, «tambien he buscado alli mas hombres que estavan en su trabajo[sic]» cuenta el pedáneo de la parroquia de San Juan de Sisto sobre sus diligencias para atrapar a dos ladronas ${ }^{81}$.

Esta red de autoridades locales semi-formales está presente en el mundo rural y constituye la base del aparato represivo y el enlace entre los ciudadanos comunes y la justicia. En estos primeros tiempos del liberalismo, muchos los verían seguramente como una continuación lógica de los merinos y mayordomos señoriales, los delegados de la justicia en el Antiguo Régimen.

Sigamos con el proceso. Los pedáneos pueden dar parte a la alcaldía, que a su vez realiza diligencias antes o después de comunicarse con el juzgado. Vemos a regidores que se desplazan al lugar de los hechos para realizar indagaciones, supervisar el peritaje o entrar en una casa buscando bienes robados; a veces delegan en subalternos. En un proceso de 1849, el alcalde de Xinzo envió a José Quelle, alguacil de la Alcaldía, para que «buscando a Ramon Cid, a quien ya el declarante conocia[sic], le hiciese comparecer a su presencia» y que averiguase «si tenia[sic] algunos ganados, y teniéndolos que los embargase y depositase» ${ }^{82}$.

\footnotetext{
79 ARG, Causas, caja 1042, expediente 10.

${ }^{80}$ ARG, Causas, caja 1729, expediente 7.

${ }^{81}$ ARG, Causas, caja 2143, expediente 3.

${ }^{82}$ ARG, Causas, caja 1881, expediente 1.
}

Hispania, 2020, vol. LXXX, n. ${ }^{\circ}$ 264, enero-abril, págs. 169-199, ISSN: 0018-2141, e-ISSN: 1988-8368 
Un ejemplo quizás ayude a ilustrar cómo los procedimientos judiciales seguían dependiendo de la colaboración de los vecinos y los cargos no profesionales incluso en un punto avanzado del proceso. En 1854 se siguió una causa contra el molinero José Rodríguez, alias Brincos. En un primer momento lo detuvo la Guardia Civil, pero como las sospechas contra él eran solo de hurto, lo volvieron a poner en libertad. El juzgado de Xinzo de Limia lo reclamó el 27 de junio, si bien el oficio no llegó a la parroquia hasta la noche del 3 de julio. Para llevarlo al juzgado se reunieron tres o cuatro hombres, entre los que se contaban el pedáneo, un alguacil auxiliar (entendemos que del juzgado) y un vigario (interpretamos que un vecino requerido para el caso y en ese sentido vicario del poder municipal o del juzgado). Rodríguez no les recibió muy bien: «ni me presento ni quiero. Venid aca[sic], carajo, que os han de llevar los demonios». En este caso, no lo atraparon: «será mejor lo persiga y arreste la Guardia Civil: pues es sujeto de muy malas intenciones» y que «si los civiles vienen para arrestarlo que vengan de noche», declaró uno de los frustrados agentes de la ley ${ }^{83}$.

Una vez finalizado el proceso penal, las declaraciones de los pedáneos y los vecinos permitían identificar los bienes de los procesados en una época en la que el Estado no conocía directamente el patrimonio de los acusados. Si en este paso los vecinos ocultaban algunas propiedades del reo por compasión, o las delataban para hacerse con ellas en la subasta, no lo dicen nuestras fuentes.

El organigrama del Estado central, en especial la Guardia Civil y los gobernadores civiles, eran eficaces para perseguir el bandolerismo o los delincuentes fugados. Encontramos a un acusado de robo en Cervo (partido de Viveiro) al que devuelve a Galicia el gobernador civil de Bilbao ${ }^{84}$. Además, las autoridades municipales y las fuerzas de seguridad eran complementarias, y los protocolos de actuación, maleables en función de las circunstancias. Vemos cómo el alcalde de Boiro pide a los carabineros que realicen un registro ${ }^{85}$. En al menos una ocasión, la Guardia Civil detuvo a un sospechoso y lo llevó ante el secretario del ayuntamiento ${ }^{86}$. El 23 de agosto de 1849 el celador del barrio del Pilar, en Santiago, «fue llamado por un Guardia civil [sic] para que le auxiliase con dos testigos $\rangle^{87}$.

Pero debemos tener presentes tres puntos. En primer lugar, si bien la estructura de la justicia había sufrido grandes transformaciones desde el Antiguo Régimen, las primeras diligencias y la persecución del delito en las zonas rurales seguían dependiendo de las autoridades municipales y de sus representantes, elegidos discrecionalmente y, por tanto, pasaban por las élites locales, con

\footnotetext{
${ }^{83}$ Según el propio Brincos, se limitó a escaparse, ARG, Causas, caja 1884, expediente 2.

${ }^{84}$ ARG, Causas, caja 1704, expediente 4.

${ }^{85}$ ARG, Causas, caja 1296, expediente 3.

${ }^{86}$ ARG, Causas, caja 1292, expediente 7.

${ }^{87}$ ARG, Causas, caja 1420, expediente 1.
}

Hispania, 2020, vol. LXXX, n. ${ }^{\circ}$ 264, enero-abril, págs. 169-199, ISSN: 0018-2141, e-ISSN: 1988-8368 https://doi.org/10.3989/hispania.2020.006 
un amplio espacio para la corrupción y las presiones. En segundo lugar, este sistema permitía que la justicia llegase a una población dispersa de manera bastante efectiva. Los pedáneos y celadores no eran profesionales, pero estaban cerca, podían reclutar ayudantes en el lugar y actuar rápidamente (y sin demasiado respeto por las garantías procesales) contra los criminales.

Finalmente, señalaremos que la persecución de los pequeños delitos contra la propiedad se iniciaba por parte de los afectados y sus vecinos, y no surgía por la actividad fiscalizadora del Estado. Sin las denuncias de los robados y la colaboración vecinal, el sistema no hubiera funcionado.

\section{CONCLuSiones}

Las estadísticas de las que disponemos para el crimen español señalan un alto nivel de delitos contra la propiedad, tanto de forma absoluta como relativa, en la transición entre las décadas de 1850 y 1860. En Galicia, aunque el delito económico parece ir en un lento ascenso desde 1836 hasta 1850 , el pico parece producirse en los años centrales de esta década, siguiendo con algo de retraso la crisis de subsistencias que se inició en 1852 y disminuyendo después del descenso del precio del grano.

Durante la crisis se produjo un aumento de los crímenes de supervivencia, en los que se robaban alimentos o se buscaba satisfacer necesidades inmediatas. Hay una elevada participación del proletariado rural, incluyendo a trabajadores bien integrados a los que una situación extraordinaria (que combinaba altos precios de los alimentos con la falta de jornales en el campo y la crisis de sectores que servían de complemento a la economía agraria) forzaba al crimen.

La mayoría de la población no recurría al crimen como estrategia de supervivencia en circunstancias normales, como sí lo hacían algunas franjas de población marginal, dado que los riesgos asociados eran altos. La ley castigaba con dureza los pequeños delitos contra la propiedad, no solo con penas de prisión, sino haciendo que los acusados cargasen con gastos económicos que dejaban literalmente en la ruina a las economías modestas. Los jueces no dejaban de castigar a los que delinquían empujados por necesidades vitales, aunque a veces fueran algo más tolerantes con ellos.

En la persecución y castigo del robo y el hurto tuvieron un papel importante dos instituciones relativamente nuevas, los juzgados de partido y la Guardia Civil, que prestaban profesionalidad y alcance al aparato represor. Pero, sobre todo en el medio rural, la delincuencia fue perseguida por las autoridades locales. Los representantes del municipio en las parroquias, los celadores y pedáneos, ocupaban un nicho similar al de sus antecesores en el Antiguo Régimen, y tenían un papel fundamental en la detección del crimen en un marco de población dispersa. Resultaban también esenciales en otras partes del proceso

Hispania, 2020, vol. LXXX, n. ${ }^{\circ} 264$, enero-abril, págs. 169-199, ISSN: 0018-2141, e-ISSN: 1988-8368 https://doi.org/10.3989/hispania.2020.006 
penal, como la instrucción de diligencias o el cobro de las costas. La represión de los ladrones no hubiera sido posible sin el papel como denunciantes de vecinos y afectados.

\section{Bibliografía}

Alonso Álvarez, Luis, «La crisis de la economía tradicional: continuidad y cambio en la Galicia del siglo XIX», en Jesús De Juana y Julio Prada (coords.), Historia contemporánea de Galicia, Barcelona, Ariel, 2005: 33-82.

Balboa López, Xesús, O monte en Galicia, Vigo, Edicións Xerais de Galicia, 1990.

Bass, Hans H., «The crisis in Prussia», en Comarc Ó Gráda, Richard Paping y Eric Vanhaute (eds.), When the potato failed: causes and effects of the 'last' European subsistence crisis, 1845-1850, Turnhoult, Brepols, 2007: 185-212.

Carballo Gende, Enrique, «Salieron desafiados a navaja»: la violencia cotidiana, el crimen y sus interpretaciones en la provincia de A Coruña (1850-1900), trabajo de fin de máster presentado en la Universidade de Santiago de Compostela, 2018.

Cardesín, José María, Tierra, trabajo y reproducción social en una aldea gallega (s. XVIII-XX), Muerte de unos, vida de otros, Madrid, Ministerio de Agricultura Pesca y Alimentación, Secretaría General Técnica, 1992.

Daly, Mary E., «Something old and something new, Recent research on the Great Irish Famine», en Comarc O Gráda, Richard Paping y Eric Vanhaute (eds.), When the potato failed: causes and effects of the 'last' European subsistence crisis, 1845 1850, Turnhoult, Brepols, 2007: 59-78.

De Juana López, Jesús y Vázquez González, Alejandro, «Población y emigración en Galicia», en Jesús De Juana y Julio Prada (coords.), Historia contemporánea de Galicia, Barcelona, Ariel, 2005: 393-440.

Díaz Marín, Pedro, «Subsistence crisis and popular protest in Spain. Th emotines of 1847», en Comarc Ó Gráda, Richard Paping y Eric Vanhaute (eds.), When the potato failed: causes and effects of the 'last' European subsistence crisis, 1845 1850, Turnhoult, Brepols, 2007: 267-292.

Domínguez Castro, Luís, «Agrarismo y sociedadcampesina en Galicia», en Jesús De Juana y Julio Prada (coords.), Historia contemporánea de Galicia, Barcelona, Ariel, 2005: 461-492.

Domínguez Martín, Rafael, «La mercantilización de los campesinos en España, 18601880: un intento de estimación», en Lourenzo Fernández Prieto y Xesús Balbóa López (eds.), La sociedad rural en la España contemporánea. Mercado y patrimonio, Sada, Ediciós do Castro, 1996.

Fernández Prieto, Lourenzo, «Las transformaciones económicas», en Jesús De Juana y Julio Prada (coords.), Historia contemporánea de Galicia, Barcelona, Ariel, 2005: 141-167.

Gadd, Carl-Johan, «On the edge of a crisis: Sweden in the 1840s», en Comarc Ó Gráda, Richard Paping y Eric Vanhaute (eds.), When the potato failed: causes and effects of the 'last' European subsistence crisis, 1845-1850, Turnhoult, Brepols, 2007: 313-342. 
Gimeno Agius, José, «El crimen en España», Revista de España, 151 (Madrid, 1885): 493-519.

Gómez Bravo, Gutmaro, Crimen y castigo: Cárceles, delito y violencia en la España del siglo XIX, tesis doctoral, Universidad Complutense de Madrid, 2004.

Henriksen, Ingrid, "A disaster seen from the periphery. The case of Denmark», en Comarc Ó Gráda, Richard Paping y Eric Vanhaute (eds.), When the potato failed: causes and effects of the 'last' European subsistence crisis, 1845-1850, Turnhoult, Brepols, 2007: 293-312.

Iglesias Estepa, Raquel, Las quiebras del orden cotidiano, tesis doctoral, Universidade de Santiago de Compostela, 2004.

López Gómez, Pedro, La Real Audiencia de Galicia y el Archivo del Reino, Santiago de Compostela, Xunta de Galicia, 1995.

Mahlerwein, Gimbsheim, «The consequences of the potato blight in South Germany», en Comarc Ó Gráda, Richard Paping y Eric Vanhaute (eds.), When the potato failed: causes and effects of the 'last' European subsistence crisis, 1845-1850, Turnhoult, Brepols, 2007: 213-222.

Martínez Ruiz, Enrique, La delincuencia contemporánea. Introducción a la delincuencia isabelina, Granada, Universidad de Granada, 1982.

Melón Jiménez, Miguel Ángel, Los tentáculos de la hidra: contrabando y militarización del orden público en España (1784-1800), Cáceres/Madrid, Universidad de Extremadura, Servicio de Publicaciones/Sílex, 2009.

Ó Gráda, Cormac, «Ireland's Great Famine. An overview», en Comarc Ó Gráda, Richard Paping y Eric Vanhaute (eds.), When the potato failed: causes and effects of the 'last' European subsistence crisis, 1845-1850, Turnhoult, Brepols, 2007: 43-58.

Paping, Richard y Tassenaar, Vincent, «The consequences of the potato disease in the Netherlands 1845-1860: a regional approach», en Comarc Ó Gráda, Richard Paping y Eric Vanhaute (eds.), When the potato failed: causes and effects of the 'last' European subsistence crisis, 1845-1850, Turnhoult, Brepols, 2007: 149-184.

Rodríguez Galdo, María Xosé y Dopico, Fausto, Crisis agrarias y crecimiento económico en Galicia en el siglo XIX, Sada, Ediciós do Castro, 1981.

Saavedra Fernández, Pegerto, A vida cotiá en Galicia de 1550 a 1850, Santiago de Compostela, Servicio de publicacións da Universidade de Santiago de Compostela, 1992.

Soto Fernández, David, Transformacións productivas da agricultura galega contemporánea. Da agricultura orgánica á revolución verde, tesis de doctorado defendida en la Universidade de Santiago de Compostela, 2002.

Vanhaute, Eric, "“So worthy an example to Ireland". The subsistence and industrial crisis of 1845-1850 in Flanders», en Comarc Ó Gráda, Richard Paping y Eric Vanhaute (eds.), When the potato failed: causes and effects of the 'last' European subsistence crisis, 1845-1850, Turnhoult, Brepols, 2007: 123-148.

Vanhaute, Eric, Paping, Richard y Ó Gráda, Cormac, «The European subsistence crisis of 1845-1850: a comparative perspective», en Comarc Ó Gráda, Richard Paping y EricVanhaute(eds.), When the potato failed: causes and effects of the 'last' European subsistence crisis, 1845-1850, Turnhoult, Brepols, 2007: 15-42. 
Vesentini, Frédéric, «Gouverner et punir en temps de crise économique. Les pratiques pénales dans la Belgique du milieu du XIXe siècle», Crime, histoire \& societés, 11/1 (Ginebra, 2007): 113-132.

Vivier, Nadine, «The crisis in France. A memorable crisis but not a potato crisis», en Comarc Ó Gráda, Richard Paping y Eric Vanhaute (eds.), When the potato failed: causes and effects of the 'last' European subsistence crisis, 1845-1850, Turnhoult, Brepols, 2007: 223-246,

Walker, Samuel, Popular justice: a history of American criminal justice, Nueva York, Oxford University Press, 1980.

Recibido: $21 / 01 / 2019$

Aceptado: 03/09/2019 